[Agr. Biol. Chem., Vol. 35, No. 6, p. 843 847, 1971]

\title{
Effect of Oxidized Polyamines on the Infectivity of $\phi$ X174 DNA
}

\author{
By Keiichiro Nishimura, Tohru Komano, Hideaki Yamada* \\ and Hiroshi Fukami** \\ Department of Agricultural Chemistry, Kyoto University \\ *Research Institute for Food Science, Kyoto University \\ **Pesticide Research Institute, Kyoto University
}

Received October 26, 1970

\begin{abstract}
Oxidized spermine and oxidized spermidine inhibited markedly the infectivity of the $6 \mathrm{M}$-urea treated $\phi \times 174$ particle, whereas they did not inactivate the infectivity of the untreated phage particle. They also markedly inhibited the infectivity of $\phi \times 174$ DNA, while $0 \mathrm{~N} 174$ RF I DNA was less sensitive to these reagents. These facts suggested that oxidized polyamines could react with phage DNA.

The possible reasons of the insensitivity of phage $\phi \times 174$ particle and less sensitivity of $\phi \mathrm{X} 174 \mathrm{RF}$ I DNA to these reagents were discussed.
\end{abstract}

Oxidized polyamines, the oxidized products of naturally occurring spermine and spermidine by beef plasma amine oxidase, have been shown to be toxic for some bacteriophages. ${ }^{1-3)}$ Oxidized spermine forms a complex with DNA of phage $T_{5}$, and the complex is injected into the host cells on infection." The oxidized spermine also forms a complex with DNA of phage $\lambda$, and whereas the complex is injected into host cells, it does not form the mature phages. ${ }^{5}$

When phages $\phi \mathrm{X} 174$ and $\mathrm{T}_{4}$, insensitive to oxidized spermine, are dialyzed exhaustively, these phages become susceptible to the reagent. $^{5)}$ On the contrary, phages $\mathrm{P} 465$ and $T_{7}$, which are inactivated markedly by oxidized

1) U. Bachrach, C. W. Tabor and H. Tabor, Biochim. Biophys. Acta, 78, 768 (1963).

2) H. Fukami, I. Tomida, T. Morino, H. Yamada, T. Oki, H. Kawasaki and K. Ogata, Biochem. Biophys. Res. Commun., 28, 19 (1967).

3) T. Oki, H. Kawasaki, K. Ogata, H. Yamada, I. Tomida, T. Morino and H. Fukami, Agr. Biol. Chem., 32, 1849 (1968).

4) U. Bachrach and J. Leibovici, J. Mol. Biol., 19, $120(1966)$.

5) T. Oki, H. Kawasaki, K. Ogata, H. Yamada, I. Tomida, T. Morino and H. Fukami, Agr. Biol, Chem., 33, 994 (1969). spermine, become insensitive by the pretreatment with spermine. ${ }^{5}$ ' These facts suggest that the oxidized polyamines compete with polyamines in reaction with phage DNA.

It is expected that the toxicity of oxidized polyamines is caused primarily by their binding to phage DNA. Effects of oxidized polyamines on the infectivity of urea-treated $\phi \mathrm{X} 174$ particles and $\phi \times 174$ DNA were therefore examined.

The present work deals with the inactivation of urea-treated $\phi \times 174$ particles, infectious $\phi \mathrm{X} 174$ DNA (single stranded circular DNA), and its replicative form DNA (RF I: double stranded closed circular DNA) by oxidized spermine, oxidized spermidine and oxidized $\mathrm{N}$-n-butyl propan-1,3-diamine.

\section{MATERIALS AND METHODS}

Media. TKB medium was described by Denhardt and Sinsheimer.6 TPG-CA medium was described by Lindquist and Sinsheimer in which casamino

6) D. T. Denhardt and R. L. Sinsheimer, J. Mol. Biol., 12, 641 (1965).

7) B. H. Lindqvist and R. L. Sinsheimer, ibid., $28,87(1967)$. 
acid was used instead of amino acid mixture. $3 \times D$, PA and PAM media were described by Guthrie and Shinsheimer. ${ }^{81}$ Dilution buffer contained $0.05 \mathrm{M}$-tris and $0.01 \mathrm{M}$-sodium borate $(\mathrm{pH} 8.0)$.

Bacteria and phages. E. coli K12W6 grown in $3 \mathrm{XD}$ medium was used for the preparation of spheroplasts. $E$. coli HF4714 grown in TKB medium was used for the titration of the phage. E. coli $\mathrm{C}_{\mathrm{N}}$ grown in TPG medium enriched with casamino acid was used for the preparation of phage $\phi \times 174$ am 3 and RF I.

$\phi X 174$ am 3 was purified by the method of Sedat and Sinsheimer ${ }^{91}$ and was used throughout the experiments.

Enzymes and chemicals. Crystalline egg white lysozyme was purchased from Sigma Chemical Company. Highly purified amine oxidase was prepared from beef plasma by the method of Yamada and Yasunobu. ${ }^{301}$

Spermine tetrahydrochloride and spermidine trihydrochloride were the products of Sigma Chemical Company.

Oxidized spermine, oxidized spermidine and oxidized $\mathrm{N}$ - $n$-butyl propan-1,3-diamine were prepared by the treatment with beef plasma amine oxidase as described previously. ${ }^{3}$

Spheroplast. Spheroplasts were prepared from $E$. coli K12W6 by the modified method of Guthrie and Sinsheimer. ${ }^{8}$ Cells grown to $5 \times 10^{8} / \mathrm{ml}$ in $30 \mathrm{ml}$ of $3 X D$ medium were centrifuged and the pellet was suspended in $0.35 \mathrm{ml}$ of $1.5 \mathrm{M}$-sucrose. The following solutions were added in order with gentle mixing after each: $0.26 \mathrm{ml}$ of $20 \%$ gelatin solution (sterilized), $0.2 \mathrm{mI}$ of $2 \mathrm{mg} / \mathrm{ml}$ Iysozyme solution, $0.4 \mathrm{ml}$ of $4 \%$ EDTA and $10 \mathrm{ml}$ of PA medium. The mixture was incubated at room temperature for $2 \mathrm{hr}$, to which was added $0.5 \mathrm{ml}$ of $50 \% \mathrm{MgSO}_{4}$ solution containing $10 \%$ sucrose.

Urea treatment. The phage spikes of $\phi \mathrm{X} 174$ were removed by the modified method of Edgell et al.11 Three volumes of $8 \mathrm{M}$-urea in $0.01 \mathrm{M}$-tris buffer $(\mathrm{pH}$ 8.0 ) were added to 1 volume of the phage solution,

8) G. D. Guthrie and R. L. Sinsheimer, Biochim. Biophys. Acta, 72, 290 (1963).

9) J. Sedat and R. L. Sinsheimer, J. Mol. Biol., 9, 489 (1964).

10) H. Yamada and K. T. Yasunobu, J. Biol. Chem., 237, 1511 (1962).

11) M. H. Edgell, C. A. Huchison and R. L. Sinsheimer, J. Mol. Biol., 42, 547 (1969). the titer of which was adjusted to approximately $3 \times 10^{9}$ infective units per $\mathrm{ml}$. The mixture was incubated at $30^{\circ} \mathrm{C}$ for $3 \mathrm{hr}$. This was dialyzed overnight against 100 volumes of cold $0.1 \mathrm{M}-\mathrm{NaCl}$ and then against fresh 100 volumes of the same solution for an additional $5 \mathrm{hr}$.

Phage DNA and RF I. Phage $\phi \times 174$ DNA was extracted from purified phage particles by the hot phenol method.81

RF I DNA was isolated and purified by the method of Komano and Sinsheimer. ${ }^{12}$

Infectivity assay. The infectivity assay of the DNA was performed by the reported procedure. ${ }^{8)}$ The infectivity assay of urea-treated $\phi \times 174$ particle was also performed by the same procedure, in which $0.4 \mathrm{ml}$ of urea-treated phage particle solution was used instead of DNA solution.

\section{RESULTS AND DISCUSSION}

When phage $T_{5}$, a titer of $10^{8}$ p.f.u., was treated with $0.6 \mathrm{mM}$ of oxidized spermine or oxidized spermidine at $30^{\circ} \mathrm{C}$ for $90 \mathrm{~min}$, survival titer was usually less than 100 . Phage $\phi \mathrm{X} 174$ was, on the other hand, unaffected under the same conditions.

When $6 \mathrm{M}$-urea treated $\phi \mathrm{X} 174$ particles were incubated with spheroplasts without pre-treatment with oxidized polyamines, the yield of mature phage was about $1 \times 10^{4}$ p.f.u., while incubated with host bacteria there was no detectable amounts of phage production. ${ }^{131}$

Effect of oxidized spermine and oxidized spermidine concentrations on the inactivation of infectivity of $6 \mathrm{M}$-urea treated $\phi \mathrm{X} 174 \mathrm{par}-$ ticles was examined. The $6 \mathrm{M}$-urea treated phage particles $\left(1.4 \times 10^{8}\right.$ p.f.u. phage equivalents) pre-treated with the same volume of various concentrations of oxidized spermine or oxidized spermidine for $5 \mathrm{~min}$ at $30^{\circ} \mathrm{C}$ was incubated with spheroplasts and continued to incubate for $2 \mathrm{hr}$ in PAM medium. As shown

12) T. Komano and R. L. Sinsheimer, Biochim. Biophys. Acta, 155, 295 (1968).

13) K. Nishimura, T. Komano, H. Yamada and H. Fukami, unpublished data. 


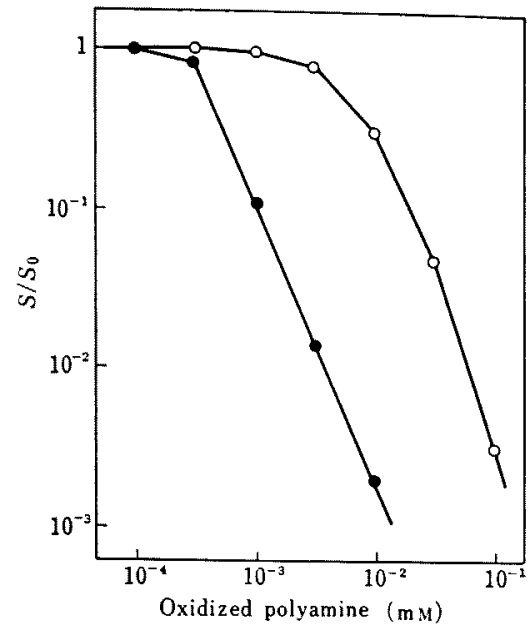

FIG. 1. Effects of Oxidized Spermine and Oxidized Spermidine Concentrations on the Infectivity of $6 \mathrm{M}$-urea Treated $\phi \mathrm{X} 174$.

An amount of $0.4 \mathrm{ml}$ of spheroplasts solution was incubated with $0.4 \mathrm{ml}$ of the $6 \mathrm{M}$-urea treated $\phi \times 174\left(7.0 \times 10^{7} / \mathrm{ml}\right.$ phage equivalents) at $30^{\circ} \mathrm{C}$ for $15 \mathrm{~min}$ which had been treated with oxidized spermine (-) or oxidized spermidine $(\mathrm{O}-\mathrm{O})$ in the dilution buffer, $\mathrm{pH} 7.0$, at $30^{\circ} \mathrm{C}$ for $5 \mathrm{~min}$. To the infected spheroplast solution were added $3.2 \mathrm{ml}$ of PAM medium and the mixture was incubated at $30^{\circ} \mathrm{C}$ for $2 \mathrm{hr}$.

in Fig. 1, the infectivity of $6 \mathrm{M}$-urea treated phage particles decreased markedly even when they were treated with $0.001 \mathrm{mM}$ of oxidized spermine or $0.01 \mathrm{mM}$ of oxidized spermidine for $5 \mathrm{~min}$.

When phage $\phi \times 174 \quad\left(1.4 \times 10^{8}\right.$ p.f.u. $)$ was treated with $4 \mathrm{M}$-urea and dialyzed against $\mathrm{NaCl}$ solution according to the procedure of Edgell et al., it was still infectious to host bacteria $\left(5 \times 10^{4}\right.$ p.f.u. $)$ but not to sheroplasts and was unaffected even on the treatment with $0.6 \mathrm{mM}$ of oxidized polyamines. It seemed that oxidized polyamines could not penetrate into the $4 \mathrm{M}$-urea treated phage particle, as the spikes were not removed completely or the conjugation of spikes to the phage particle was reversible so that they reconstructed under the condition used in the treatment with oxidized polyamines.
The fact that the infectivity of the phage particles treated with $6 \mathrm{M}$-urea but not with $4 \mathrm{M}$-urea was decreased markedly by oxidized polyamines might indicate that the spikes were removed from the phage particles as described by Edgell et al.: these reagents might enter into the phage particles through the parts to which the spikes had been attached and reacted with the phage DNA and then the particles might be inactivated.

Effect of incubation time of $6 \mathrm{M}$-urea treated phage particles with $0.001 \mathrm{mM}$ of oxidized spermine and oxidized spermidine on the infectivity was investigated. The results are shown in Fig. 2. Incubating with $0.001 \mathrm{mM}$ of oxidized spermine, the infectivity of the ureatreated phage particles was reduced with logarithmic linearlity up to $5 \mathrm{~min}$. On the other hand, the same concentration of oxidized spermidine gave no effects on the infectivity.

Effect of oxidized spermine and oxidized

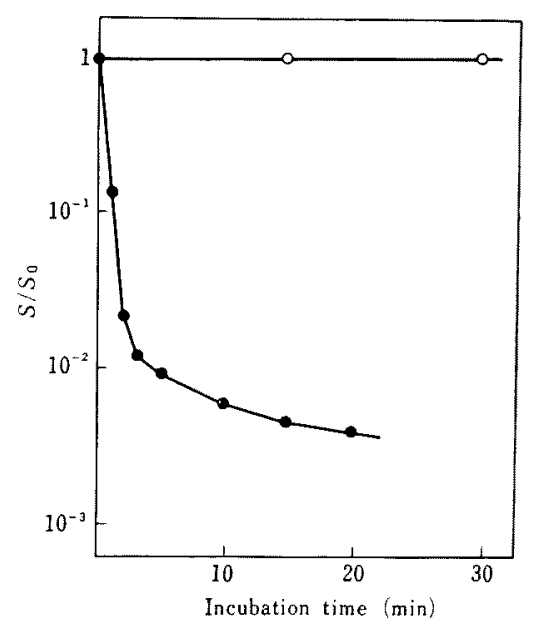

FIg. 2. Effects of Incubation Time of 6M-urea Treated $\phi \times 174$ with Oxidized Spermine and Oxidized Spermidine on the Infectivity.

Conditions of the infection were the same as described in Fig. 1. An amount of $0.2 \mathrm{ml}$ of the $6 \mathrm{M}$-urea treated $\phi \times 174\left(1.4 \times 10^{8}\right.$ p.f.u. phage equivalents) was treated with the same volume of $0.002 \mathrm{mM}$ of oxidized spermine $(-)$ ) or oxidized spermidine $(\mathrm{O}-\mathrm{O})$ at $30^{\circ} \mathrm{C}$. 


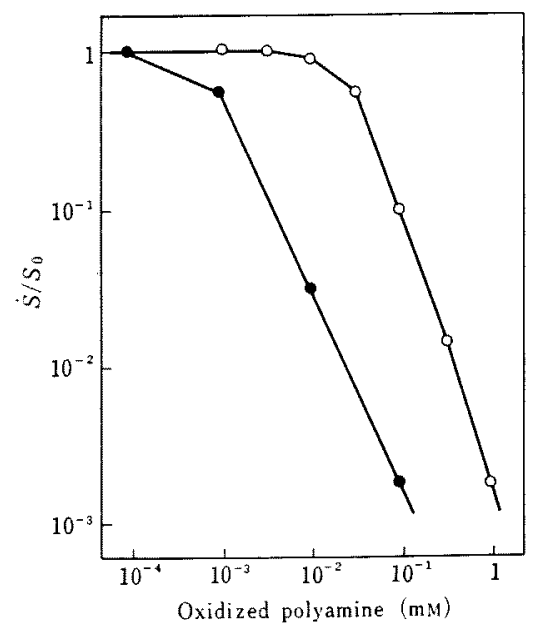

FIG. 3. Effects of Oxidized Spermine and Oxidized Spermidine Concentrations on the Infectivity of $\phi$ X174 DNA.

An amount of $0.4 \mathrm{ml}$ of spheroplasts was incubated with $0.4 \mathrm{ml}$ of $\phi \times 174$ DNA solution $\left(2 \times 10^{9}\right.$ particles) at $30^{\circ} \mathrm{C}$ for $15 \mathrm{~min}$ which had been treated with oxidized spermine - or oxidized spermidine $(\mathrm{O}-\mathrm{O})$ in the dilution buffer, $\mathrm{pH} 7.0$, at $30^{\circ} \mathrm{C}$ for $5 \mathrm{~min}$. $3.2 \mathrm{ml}$ of $\mathrm{PAM}$ medium were added to the infected spheroplast solution and the mixture was incubated at $30^{\circ} \mathrm{C}$ for $2 \mathrm{hr}$.

spermidine concentrations on the infectivity of $\phi \mathrm{X} 174$ DNA was examined. The results are shown in Fig. 3. The infectivity of $\phi \times 174$ DNA decreased markedly even when the DNA was treated with $0.1 \mathrm{~mm}$ of oxidized spermidine or $0.01 \mathrm{mM}$ of oxidized spermine for $5 \mathrm{~min}$. This indicates that $\phi$ X174 DNA interacts sufficiently with oxidized spermine and oxidized spermidine.

Effect of incubation time of $\phi \mathrm{X} 174$ DNA and RF I DNA with $0.1 \mathrm{mM}$ of oxidized spermidine and oxidized $\mathrm{N}$ - $n$-butyl propan-1,3diamine on the infectivity was examined. These reagents markedly decreased the infectivity of $\$ \mathrm{X} 174$ DNA but not that of RF I DNA, as shown in Fig. 4. The less sensitivity of RF I DNA to oxidized spermidine and oxidized N-n-butyl propan-1,3-diamine might be due to the double stranded structure of the DNA.

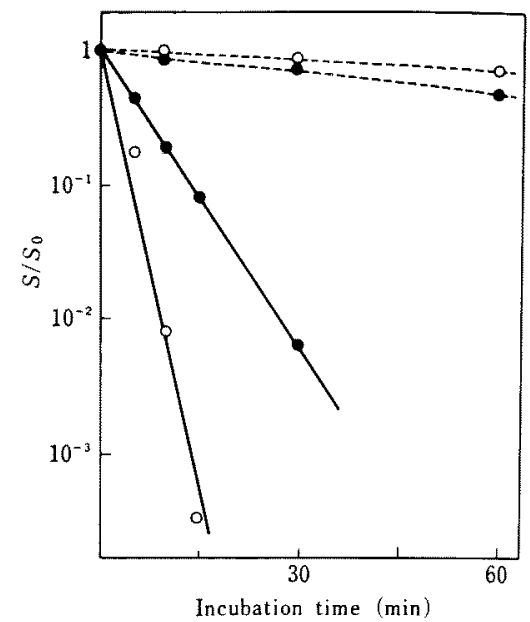

FIG. 4. Effects of Incubation Time of $\phi \times 174$ DNA and RF I DNA with Oxidized Spermidine and Oxidized N-n-Butyl Propan-1,3-diamine on the Infectivity.

Conditions of the infection were the same as described in Fig. 3. An amount of $0.2 \mathrm{ml}$ of $\phi \times 174$ DNA solution (which gave $2 \times 10^{9}$ phage particles; - $)$ and RF I DNA solution $\left(1 \times 10^{10}\right.$ single strand equivalents; ----) were treated with $0.2 \mathrm{mM}$ of oxidized spermidine $(O)$ or oxidized N-n-butyl propan-1,3-diamine (1).

Phage $\phi \times 174$ particle was not inactivated by oxidized polyamines, but fully dialyzed phage was inactivated significantly, and the infectivity of the urea-treated phage particles as well as that of the purified DNA were inhibited markedly. These facts suggested that $\phi \times 174$ DNA as well as DNA's of susceptible phages, $\mathrm{T}_{5}{ }^{4}$ and $\lambda^{51}$ could react with oxidized polyamines. The reason of insensitivity of phage $\phi \mathrm{X} 174$ particle to oxidized polyamines might be considered that the reagents could not penetrate through the coat protein or competed with polyamine(s) in phage particle, so that they could not react with phage DNA.

Effect of hydroxylamine on the infectivity of phage S13 DNA and its RF has been reported. ${ }^{141}$ The RF is fairly stable on the

14) E. S. Tessman, J. Mol. Biol., 17, 218 (1966). 
treatment with the reagent, while S13 DNA is very sensitive. The inactivation of the infectivity of $\phi \mathrm{X} 174$ DNA and RF I by hydroxylamine was therefore tested. The reagent inactivated the $\phi \times 174$ DNA but not RF I. Moreover, glyoxal gave similar curves in inactivation of $\phi \mathrm{X} 174$ DNA and RF . $^{15}$ ) These reagents are known to react with specific bases in nucleic acid. Bachrach et al. described that guanine is the most probable base

15) K. Nishimura, T. Komano, H. Yamada and H. Fukami, unpublished data. to react with oxidized polyamines. ${ }^{16)}$ It is, therefore, speculated that a loss of infectivity is caused by the binding of these oxidized polyamines to DNA. In DNA molecule, bases modified with them may inhibit the activity of replication and transcription.

Acknowledgement. The authors wish to express our sincere thanks to Mr. Takayuki Gotan for his kind help during the course of this experiment. This work supported by a Scientific Research Fund of Ministry of Education of Japan.

16) G. Eilon and U. Bachrach, Biochim. Biophys. Acta, 179, 464 (1969). 